\title{
A Discussion on the Development of Higher Vocational Students' Individual Learning Capability
}

\author{
Yan Feng \\ Research Department of Chongqing Business Vocational College, Chongqing, China \\ cqszyzcp@163.com
}

Keywords: higher vocational students, independent learning capability, current situation, training channel.

\begin{abstract}
. as an important expression of the higher vocational students' quality, the individual learning capability is analyzed in detail in this dissertation. The training channels of individual learning capability mainly include three aspects, namely, the inner subjective factor, the dominant extrinsic factor and the middle internet factor. Because of its complexity, the vocational colleges should focus on the development of students' individual learning capability and transport professional talents for the society.

The individual learning capability, particularly important for higher vocational students, refers to the learning capability of acquiring knowledge, applying knowledge, identifying and solving problem independently. Pointed by the Ministry of Education in 2000, the basic feature of the talent training in higher vocational college is to transport application-oriented talents with high-technology to adapt to the needs of community. The significance of higher vocational education lies on how to realize the students' individual learning. The famous American futurologist Alvin Toffler wrote in his Future Shock: "The illiteracy in future are not the traditional illiteracy but refers to those who can not learn”. Therefore, the development of students' individual learning capability has turned into an important mission for higher vocational college, and it has put forward higher requirements for vocational students.
\end{abstract}

\section{The current situation of the higher vocational students' individual learning capability}

Most vocational students arrive at colleges with low scores of College Entrance Examination. Without strong learning will, they are not active in learning and exploration. They don't have good learning habits or learning plan. As the training mode of vocational education focuses on students' capability and application-oriented talents, the graduates of vocational college should own rich theoretical knowledge and applicable technology. Thus, it is of great necessity to improve the students' individual learning capability to cope with the employment pressure.

\section{How to develop the students' individual learning capability}

Facing the current vocational students' individual learning capability, we need to develop and improve this capability through the following three aspects.

The inner subjective factor

The vocational students can make efforts through the following aspects as the learning capability belongs to students' inner quality. Their subjective factor is crucial for the individual learning capability, especially their decision-making power brought by the students-oriented teaching mode.

Learning plan and target

Learning plan and target are necessary for vocational students, particularly the freshmen. Because of the ending of busy high school learning, many students feel completely overwhelmed and do not know what to do. However, the vocational study directly aims at employment and the vocational students should understand the occupational plan course, make their own plan and target and prepare for the future career to learning knowledge actively.

Learning methods

Being initiative and proactive is necessary for vocational students to face various learning 
problems, improve and find their own learning methods. There is no learning approach adaptable to all. Besides, the learning method of high school is not fit for vocational students as most of their time is used for individual study. Vocational students have to learn to consult relevant reference and professional books and utilize library and internet to solve learning problems.

Learning efficiency

Vocational students should make self-evaluation and improve efficiency after their individual learning. From self-evaluation, the students will understand their own advantage and disadvantage, summarize problems and adjust the learning target and progress to improve their individual learning. What's more, the students will find their achievement and shortcoming, and acquire more confidence for individual learning after they overcome difficulties. Thus, the vocational students' individual learning capability will be enhanced.

\section{Good communication}

The individual learning capability requires the students to be independent and cooperative. It must be noted that the students should understand the significance of cooperation and mutual progress between themselves. The vocational students should participate in group activities, such as the second classroom and the club, to create learning opportunity and environment, be integrated into the collective, improve self-understanding and solve learning problems to further enhance their individual learning capability.

Learning will

For vocational students, the individual learning is a long tough period, and those who persist must have strong will power. Like a mini society, the college campus has many attractive activities disturbing the students' learning, for example, dating, shopping, and so on. Meanwhile, most students have a large amount of time to spend on their own, so the strong will power is significant for them to insist on learning and achieve good results.

The dominant extrinsic factor

In addition to the inner subjective factor, the higher vocational students' individual learning is also influenced by the dominant extrinsic factor, namely, the teacher, the college, and so on.

The teacher

Firstly, the teacher acts as guide. As the guide for developing students' individual learning capability, the teacher interacts well with students during the teaching procedure. By setting questions and encouraging students to question, the teacher guide students' individual learning. And the teacher should also explore how to interact with students as a teacher without research competence can not develop students' individual learning capability. Starting from how to establish learning target and method, and how to select correct information, the teacher's guiding role also contains his study on teaching design and resources, and students' knowledge structure and learning will to guide and develop the students' individual learning capability.

Secondly, the teacher acts as stimulator. As a stimulator, the teacher inspires students' interest and helps them develop their maximum potential. If a student is interested in learning, this is demonstrated not only in the classroom but also in his spare time. As the vocational students have much extracurricular time now, they will improve their individual learning capability and achieve satisfactory learning effect when they make full use of this extracurricular time. Interest is the best teacher. When student know the advantage and future of his profession, he will be interested in professional learning. Thus, the teacher can arouse students' interest through helping them know about their profession and career prospects. If the students experience the success of individual learning, they will be encouraged and finally realize the transition from "I have to learn" to "I want to learn”.

Thirdly, the teacher acts as supervisor. The teacher's mission includes supervising and checking the students' individual learning. He also encourages and guides the students' learning. When he evaluates his students, he should try to be objective, fair and correct. In other words, he should be aware of students' achievements and shortcomings, and analyze the reason for reference. The students' bad habits of individual learning need to be corrective and intensified by the teacher to begin their active learning. 
The school

Firstly, the school spirit and class atmosphere. Good school spirit and class atmosphere works as an important guarantee for developing the individual learning capability. The school spirit, social atmosphere of the school, is an intangible environmental factor as well as a massive educational force. The class atmosphere refers to the psychological disposition of class members. When the school spirit and class atmosphere comes into being, they will influence the whole class. Obviously, good school spirit and class atmosphere promotes students' individual learning capability.

Secondly, the management system. For students who are unwilling to learn, the management system is necessary. In other words, when the inner factor doesn't work, the extrinsic factor is utilized to make changes. During teaching and daily management, it is necessary for the school authority to establish strict management system and urge students' individual learning by pressure.

Thirdly, self-study conditions. A good comfortable learning environment, including the library, self-study room and classroom, helps students’ individual learning.

The society

Facing the increasingly fierce social competition and employment pressure, the students' individual learning has become an urgent need for our higher vocational college. As the employers need technology-based talents, students should not only learn the academic and technological knowledge but also develop the capability of individual learning that trains them to solve problems independently.

The medium factor - online learning

With the rapid development of internet technology, the online learning is increasingly significant for developing students’ individual learning capability.

To develop the capability of self-organization

The online learning contributes to the improvement of students' self-organizational capability, including self-encouragement, self-orientation, self-planning, and self-adjustment. The special environment of online learning requires certain quality and style of the learner. For example, the learner should be mature enough for scheduling study time and place and selecting proper study material. These qualities and capabilities are crucial for students' individual learning capability.

The utilization of online learning space

The individual online learning helps students enjoy the convenience of digitalization study. The students can construct "my learning space" on the web, make full use of the online resources and realize resource sharing. As the students establish their own knowledge structure, determine clear learning target and acquire study material by online browsing and reference, the online learning, which is more active and initiative, contributes to the development of individual learning capability.

\section{Conclusion}

In brief, as an important expression of the higher vocational students' quality, the development of students' individual learning capability is closely connected with three elements: the inner subjective factor, the dominant extrinsic factor and the internet factor. As it is impossible for the vocational college to teach students the knowledge that can company their life, the individual learning capability is of great significance and more professional talents will be trained through the constant improvement of students' individual learning capability.

(Note: This paper is independent study ability of higher vocational students in the National Education Science "Twelfth Five-Year Plan" key project of Ministry of education project DIA110281 stage of research.)

\section{References:}

[1] Wei Zhongen, Chen Jingyun:The Institutional Guarantee for the Development of Higher Vocational Students’ Individual Learning Capability. Education and Career, Vol. 12 (2007)

[2] Zhang Lijuan: On the Development of Higher Vocational Students' Individual Learning Capability. Journal of Zhengde College, Vol. 6 (2010) 
[3] Chen Wei:A Talk about the Development of Higher Vocational Students' Individual Learning Capability.Wisdom, Vol. 33(2010)

[4] Chang Zhiqiang:Rational Thinking of the Development of Higher Vocational Students' Individual Learning Capability. Journal of the Jiyuan Vocational Technical Institute, Vol. 12(2003) 